Military Technical College Kobry El-Kobbah, Cairo, Egypt

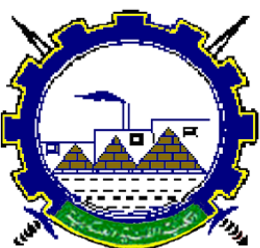

I.C.E.E.2016 $8^{\text {th }}$ International Conferenc

on

Chemical \& Environmenta Engineering 19 - 21 April 2016

\title{
PCEA -5
}

\section{Mass Transfer Rate of Selected Contaminants in Polar Organic Chemical Integrative Sampler (POCIS)}

\author{
Hamidreza Sharifan, Audra Morse
}

\begin{abstract}
Accurate measurement of persistent organic pollutants concentrations based on traditional grab sampling techniques are not always possible. Passive sampling devices represent an attractive alternative to these traditional sampling that overcomes the measurement limitations in sequestering and have higher sensivity to detect chemicals in aquatic systems. The Polar Organic Chemical Integrative Sampler (POCIS) with application of PES membrane has been used as an adsorbing device to determine sources and amounts of variety of solute organic contaminants in aqueous environment. The objective of the present paper is to study mass transfer of five water contaminants (atrazine, caffeine, bentazon, ibuprofen, atenolol) through the Water Boundary Layer (WBL) and a Polyethersulfone membrane. It followed by establishing a relationship between the sampling rate and water solubility of the compounds and comparing this at different molecular weight and equilibrium concentrations. Also to determine whether WBL effects transport rate through the membrane. All target compounds were detected and analyzed by Gas Chromatography- Mass Spectophotometry (GC-MS). An approximately linear correlation between feed concentration of compound and sampling rate has been observed.
\end{abstract}

Keywords:

Passive Sampler; Water contaminants; PES; Transfer Rate

Department of Civil, Environmental, and Construction Engineering at Texas Tech University, Texas, USA,Hamidreza.sharifan@ttu.edu 